\title{
Join distributive of super modular pair elements in super modular semi lattice.
}

\author{
Sri Rama Ravi Kumar. Emani \\ Dept.of Mathematics, V.R.Siddhartha Engineering college, Vijayawada, A.P.India.
}

\begin{abstract}
This study concerns with the concepts of join distributive, distributive elements of join semi lattice, modular and super modular semi lattice. We define a join distributive element in super modular semi lattice and obtained every join distributive element of super modular semi lattice is distributive. Also it is proved that every directed below modular semi lattice is a super modular semi lattice. It is defined a super modular pair elements in join semi lattice and proved that, in a super modular semi lattice $S$, if an element a is join distributive, the pair of elements $(a, b)$ is super modular pair elements of $S$ for $b \in S$.
\end{abstract}

\section{Introduction}

The concept of distributivity has been extended to join semi lattice by J. Katrinak (4) and of modularity by W.H.Cornish $(2,3)$. The concept of Super modular lattices were studied by Iqbalunnisa and W.B.Vasantha(4) and concept of super modularity in join semi lattices and characterization of super modular join semi lattices are analyzed by Venkateswara rao J and Sree Rama Ravi Kumar (9). In this paper the concept of join distributive element and distributive elements of join semi lattice was studied and defined join distributive element in Super modular semi lattice and obtained every join distributive element is distributive element in super modular semi lattice. Also defined super modular pair elements in super modular semi lattice and proved that, in super modular semi lattice $\mathrm{S}$, if a $\in \mathrm{S}$, is a join distributive element then the pair of elements $(\mathrm{a}, \mathrm{b})$ is super modular pair for $\mathrm{b} \in \mathrm{S}$. But converse need not be true.

1. Directed below semi lattice: A Join semi lattice $S$ is said to be directed below semi lattice, for every pair of elements $a, b$ in $S$, there exists $d$ in $S$, such that $d \leq a$ and $d \leq b$.

2. Distributive element: An element $d$ of join semi lattice $S$ is called distributive, if $x \leq d \vee$ a,

$\mathrm{x} \leq \mathrm{d} \vee \mathrm{b}$ for $\mathrm{x}, \mathrm{a}, \mathrm{b} \in \mathrm{S}$, implies there exists $\mathrm{c} \in \mathrm{S}$, such that $\mathrm{c} \leq \mathrm{a}, \mathrm{c} \leq \mathrm{b}$ and $\mathrm{x} \leq \mathrm{d} \vee \mathrm{c}$.

3.Join Distributive element: An element a in join semi lattice $S$, is said to be join distributive element, if for any $\mathrm{x}, \mathrm{y} \in \mathrm{S}, \mathrm{y} \leq \mathrm{a} \vee \mathrm{x}$ implies there exists $\mathrm{x}_{1}$ and $\mathrm{a}_{1}$ in $\mathrm{S}$ such that $\mathrm{a}_{1} \leq \mathrm{a}, \mathrm{x}_{1} \leq \mathrm{x}$ and $\mathrm{a}_{1} \vee \mathrm{x}_{1}=\mathrm{y}$.

4. Example: In a bounded semi lattice $[0,1]$ the elements 0 and 1 are join distributive elements.

5. Example for join distributive elements. Consider the semi lattice $S=\{a, b, c, d, 1\}$ as follows.

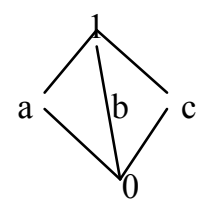

Since $\mathrm{c} \leq \mathrm{a} \vee \mathrm{b}$ for $\mathrm{c}, \mathrm{b} \in \mathrm{S}$, there does not exists $\mathrm{a}_{1} \leq \mathrm{a}, \mathrm{b}_{1} \leq \mathrm{b}$ such that $\mathrm{c}=\mathrm{a}_{1} \vee \mathrm{b}_{1}$.

Therefore $\mathrm{c}$ is not join distributive. Similarly we prove the elements $\mathrm{a}$ and $\mathrm{b}$ are also not join distributive.

6. Result: Every join distributive element of as semi lattice $(S, V)$ is distributive element.

Proof: Let an element a in join semi lattice $S$ is join distributive element, then for $x, y \in S$, with $y \leq a \vee x$, there exists $x_{1}$ and $a_{1}$ in $S$, such that $a_{1} \leq a, x_{1} \leq x$ and $a_{1} \vee x_{1}=y$. Since $y \leq a \vee y$ and

$a_{1} \vee x_{1}=y$ then $x_{1 \leq} a_{1} \vee x_{1}=y$. Thus $x_{1} \leq x$ and $x_{1} \leq y$ and $y \leq a \vee x_{1}$. Hence a is distributive element.

7. Modular Semi lattice: A join semi lattice $S$ is said to be modular if and only if $a \leq w \leq a \vee b$ implies there exists $\mathrm{y}$ in $\mathrm{S}$ such that $\mathrm{y} \leq \mathrm{b}$ and $\mathrm{w}=\mathrm{a} \vee \mathrm{y}$ for $\mathrm{a}, \mathrm{b} w \in \mathrm{S}$.

8. Super modular semi lattice: A join semi lattice $S$ is called Super modular semi lattice whenever a $\leq$ $\mathrm{x} \leq \mathrm{a} \vee \mathrm{b}, \mathrm{a} \vee \mathrm{c}, \mathrm{a} \vee \mathrm{d}$ then there exists $\mathrm{s}, \mathrm{t}, \mathrm{u}$ in $\mathrm{S}$ such that $\mathrm{s} \leq \mathrm{b}, \mathrm{c}, \mathrm{a} \vee \mathrm{d}$; $\mathrm{t} \leq \mathrm{c}, \mathrm{d}, \mathrm{a} \vee \mathrm{b}$;

$\mathrm{u} \leq \mathrm{d}, \mathrm{b}, \mathrm{a} \vee \mathrm{c}$ and $\mathrm{x}=\mathrm{a} \vee \mathrm{s} \vee \mathrm{t} \vee \mathrm{u}$.

9. Example: Let $\mathrm{S}=\{1,2,4,8,16,32\}$ be a finite chain with divisibility property. Then $\mathrm{S}$ is super modular semi lattice, by defining the operation $\mathrm{a} \vee \mathrm{b}=1 \mathrm{~cm}\{\mathrm{a}, \mathrm{b}\}$, when $1 \leq 4 \leq 1 \mathrm{~V} 4,1 \mathrm{~V} 8,1 \mathrm{~V} 16$ then there exists $4,2,1$ in $\mathrm{S}$ such that $4 \leq 4,8,1 \vee 16 ; 2 \leq 8,16,1 \vee 4 ; 1 \leq 16,4,1 \vee 8$ and $4=1 \vee 4 \vee 2 \vee 1$.

10. Theorem: Every directed below modular semi lattice is a Super modular.

Proof: Let $\mathrm{S}$ be a modular semi lattice. Let $\mathrm{w}, \mathrm{b} \in \mathrm{S}$, then for $\mathrm{w} \leq \mathrm{w} \leq \mathrm{w} \vee \mathrm{b}$, there exists $\mathrm{y}$ in $\mathrm{S}$ such that $\mathrm{y} \leq \mathrm{b}$ and $\mathrm{w}=\mathrm{w} \vee \mathrm{y}$. Hence $\mathrm{w}=\mathrm{w} \vee \mathrm{y} \geq \mathrm{y}$, implies $\mathrm{y} \leq \mathrm{w}$ and $\mathrm{y} \leq \mathrm{b}$ for $\mathrm{w}, \mathrm{b} \in \mathrm{S}$. Therefore modular semi lattice $\mathrm{S}$ is 
directed below. Now Suppose $\mathrm{S}$ is directed below modular semi lattice. To prove that $\mathrm{S}$ is super modular. For a, $\mathrm{b} \in \mathrm{S}, \mathrm{a} \leq \mathrm{x} \leq \mathrm{a} \vee \mathrm{b}$ there exists $\mathrm{s}$ in $\mathrm{S}$ such that $\mathrm{s} \leq \mathrm{b}$ and $\mathrm{x}=\mathrm{a} \vee \mathrm{s}$. Similarly $\mathrm{a} \leq \mathrm{x} \leq \mathrm{aVc}$, there exists $\mathrm{t}$ in $\mathrm{S}$ such that $\mathrm{t} \leq \mathrm{c}$ and $\mathrm{x}=\mathrm{aVt}$ and for $\mathrm{a} \leq \mathrm{x} \leq \mathrm{aVd}$ there exists $\mathrm{u}$ in $\mathrm{S}$ such that $\mathrm{u} \leq \mathrm{d}$ and $\mathrm{x}=\mathrm{aVu}$. Then for $\mathrm{a} \leq \mathrm{x} \leq \mathrm{aVb}, \mathrm{aVc}$, $a \vee d$ there exists s,t,u in $S$ such that $s \leq b, t \leq c, u \leq d$ and $x=a \vee s \vee t V u$. Since $x \leq a \vee d$ and $x=a \vee s$, we have $a \vee s \leq$ $\mathrm{aVd}$, implies $\mathrm{s} \leq \mathrm{aV} \mathrm{s} \leq \mathrm{aVd}$; implies $\mathrm{s} \leq \mathrm{aVd}$. Also, since $\mathrm{x} \leq \mathrm{a} \vee c$ and $\mathrm{x}=\mathrm{aV} \mathrm{s}$, we have $\mathrm{a} \vee \mathrm{s} \leq \mathrm{aVc}$; implies $\mathrm{s} \leq \mathrm{c}$. Hence $\mathrm{s} \leq \mathrm{b}, \mathrm{c}, \mathrm{a} \mathrm{V}$. Similarly we can prove that $\mathrm{t} \leq \mathrm{c}, \mathrm{d}, \mathrm{a} \vee \mathrm{b}$ and $\mathrm{u} \leq \mathrm{d}, \mathrm{b}, \mathrm{a} \mathrm{c}$. Therefore $\mathrm{S}$ is super modular.

11.Join distributive element in super modular semi lattice: An element a is said to be join distributive element in super modular semi lattice if $\mathrm{x} \leq \mathrm{t} \leq \mathrm{a} \vee \mathrm{x}, \mathrm{a} \vee \mathrm{y}, \mathrm{a} \vee \mathrm{z}$, there exists $\mathrm{a}_{1} \leq \mathrm{a}, \mathrm{x}_{1} \leq \mathrm{x}, \mathrm{y}_{1} \leq \mathrm{y}, \mathrm{z}_{1} \leq \mathrm{z}$ such that $\mathrm{x}_{1} \vee \mathrm{y}_{1} \vee \mathrm{z}_{1} \vee \mathrm{a}_{1}=\mathrm{t}$.

12. Example: Let $S=\{1,2,4,8\}$ be a finite chain with divisibility order. Define $a \vee b=1 \mathrm{~cm}\{a, b\}$ for $a, b \in S$, then clearly $\mathrm{S}$ is a super modular semi lattice. And an element 1 in $\mathrm{S}$ is a join distributive element, since $2 \leq 8 \leq 1 \mathrm{~V} 2$, $1 \mathrm{~V} 4,1 \mathrm{~V} 8$, there exists $1,2,4,8$ in $\mathrm{S}$ such that $1 \leq 1 ; 2 \leq 2 ; 4 \leq 4 ; 8 \leq 8$ and $1 \mathrm{~V} 2 \mathrm{~V} 4 \mathrm{~V} 8=8$. Similarly the elements 2,4 and 8 are also join distributive elements of $\mathrm{S}$.

13. Theorem: Every join distributive element of super modular semi lattice $S$ is a distributive.

Proof: Let an element $\mathrm{a}$ in $\mathrm{S}$ be a join distributive element, then for $\mathrm{x} \leq \mathrm{t} \leq \mathrm{a} \vee \mathrm{x}, \mathrm{a} \vee \mathrm{y}, \mathrm{a} \vee \mathrm{z}$, there exists $\mathrm{a}_{1} \leq \mathrm{a}$, $\mathrm{x}_{1} \leq \mathrm{x}, \mathrm{y}_{1} \leq \mathrm{y}, \mathrm{z}_{1} \leq \mathrm{z}$ such that $\mathrm{x}_{1} \vee \mathrm{y}_{1} \vee \mathrm{z}_{1} \vee \mathrm{a}_{1}=\mathrm{t}$. To prove that a is distributive element of $\mathrm{S}$, for $\mathrm{x} \leq \mathrm{a} \vee \mathrm{x}, \mathrm{x} \leq \mathrm{a} \vee$ $\mathrm{y}$, there exists $\mathrm{x}_{1} \leq \mathrm{x} \leq \mathrm{aVy}$, implies $\mathrm{x}_{1} \leq \mathrm{aVy}$, implies $\mathrm{aV} \mathrm{x}_{1} \leq \mathrm{aVy}$; implies $\mathrm{x}_{1} \leq \mathrm{y}$. Also for $\mathrm{x} \leq \mathrm{t} \leq \mathrm{aV} \mathrm{x}$, there exists $\mathrm{a}_{1} \leq \mathrm{a}, \mathrm{x}_{1} \leq \mathrm{x}$ such that $\mathrm{x}_{1} \vee \mathrm{a}_{1}=t$; implies $\mathrm{x} \leq \mathrm{x}_{1} \vee \mathrm{a}_{1} \leq \mathrm{a} \vee \mathrm{x}$; implies $\mathrm{x} \leq \mathrm{a}_{1} \vee \mathrm{x}_{1} \leq \mathrm{a} \vee \mathrm{x}_{1}$; implies $\mathrm{x} \leq \mathrm{a} \vee \mathrm{x}_{1}$ . Therefore for $\mathrm{x} \leq \mathrm{a} \vee \mathrm{x}$ and $\mathrm{x} \leq \mathrm{a} \vee \mathrm{y}$, there exists $\mathrm{x}_{1} \leq \mathrm{x}$ and $\mathrm{x}_{1} \leq \mathrm{y}$ also $\mathrm{x} \leq \mathrm{a} \vee \mathrm{x}_{1}$.

Hence a is distributive element of $\mathrm{S}$.

14.Super modular pair elements: Let $(S, v)$ be a join semi lattice and $a, b \in S$, we call $(a, b)$ a super modular pair denoted by a $S_{m} b$, if for $b \leq t \leq a \vee x, a \vee y, a \vee z$, there exists $x_{1}, y_{1}, z_{1}$ in $S$, such that $x_{1} \leq x, y, a \vee z ; y_{1} \leq y$ , $\mathrm{z}, \mathrm{a} \vee \mathrm{x} ; \mathrm{z}_{1} \leq \mathrm{z}, \mathrm{x}, \mathrm{a} \vee \mathrm{y}$ and $\mathrm{x}_{1} \vee \mathrm{y}_{1} \vee \mathrm{z}_{1} \vee \mathrm{a}_{1}=\mathrm{t}$ for $\mathrm{t} \in \mathrm{S}$.

15. Example: Let $S=\{1,2,4,8,16\}$ be a finite chain with divisibility property such that $a \vee b=1 \mathrm{~cm}(\mathrm{a}, \mathrm{b})$. Since $2 \leq 4 \leq 1 \mathrm{~V} 4,1 \mathrm{~V} 8,1 \mathrm{~V} 16$; there exists $1,2,4$ in $\mathrm{S}$ such that $1 \leq 4,2 \leq 8,4 \leq 16$ such that $1 \leq 4,8,1 \mathrm{~V} 16$; $2 \leq 8,16,1 \vee 4 ; 4 \leq 16,4,1 \vee 8$ and $1 \vee 2 \vee 4 \vee 1=4$. Thus $(1,2)$ is super modular pair elements of $S$.

16. Theorem: Let $(S, V)$ be a Super modular semi lattice and $a, b \in S$, if a is join distributive element of $S$ then a $S_{m}$ b. Converse need not be true.

Proof: Let an element a be join distributive element of super modular semi lattice $\mathrm{S}$. To prove that $(\mathrm{a}, \mathrm{b}) \mathrm{be}$ a super modular pair elements of $\mathrm{S}$, consider $\mathrm{b} \leq \mathrm{t} \leq \mathrm{a} \vee \mathrm{x}, \mathrm{a} \vee \mathrm{y}, \mathrm{a} \vee \mathrm{z}$, for $\mathrm{a}, \mathrm{b}, \mathrm{x}, \mathrm{y}, \mathrm{z} \in \mathrm{S}$, since $\mathrm{a}$ is join distributive element and for $\mathrm{x} \leq \mathrm{t} \leq \mathrm{a} \vee \mathrm{x}, \mathrm{a} \vee \mathrm{y}, \mathrm{a} \vee \mathrm{z}$, there exists $\mathrm{x}_{1} \leq \mathrm{x}, \mathrm{a}_{1} \leq \mathrm{a}$ such that $\mathrm{a}_{1} \vee \mathrm{x}_{1}=$. Since $\mathrm{x} \leq \mathrm{t} \leq \mathrm{a} \vee$ $y$ and $t=a_{1} \vee x_{1}$, we have $a_{1} \vee x_{1} \leq a \vee y$ then $x_{1} \leq y$ as $a_{1} \leq a$. Also for $x \leq t \leq a \vee z$ and $x_{1} \leq x$, we have $x_{1} \leq x \leq t \leq$ $\mathrm{a} \vee \mathrm{z}$ implies $\mathrm{x}_{1} \leq \mathrm{a} \vee \mathrm{z}$ as $\mathrm{x} \leq \mathrm{x}$. Thus for $\mathrm{b} \leq \mathrm{t} \leq \mathrm{a} \vee \mathrm{x}$, there exists $\mathrm{x}_{1} \leq \mathrm{x}, \mathrm{a} \vee \mathrm{z}$, $\mathrm{y}$ such that $\mathrm{a}_{1} \vee \mathrm{x}_{1}=$ t. Similarly for $\mathrm{b} \leq \mathrm{t} \leq \mathrm{a} \vee \mathrm{y}, \mathrm{a} \vee \mathrm{z}$ there exists $\mathrm{y} \leq \mathrm{y}, \mathrm{z}, \mathrm{a} \vee \mathrm{x}$ and $\mathrm{z} \leq \mathrm{z}, \mathrm{x}, \mathrm{a} \vee \mathrm{y}$ with $\mathrm{a}_{1} \vee \mathrm{y}_{1}=\mathrm{t}$ and $\mathrm{a}_{1} \vee \mathrm{z}_{1}=\mathrm{t}$.

Therefore for $\mathrm{b} \leq \mathrm{t} \leq \mathrm{a} \vee \mathrm{x}, \mathrm{a} \vee \mathrm{y}, \mathrm{a} \vee \mathrm{z}$, there exists $\mathrm{x}_{1}, \mathrm{y}_{1}, \mathrm{z}_{1}$ in $\mathrm{S}$, such that $\mathrm{x}_{1} \leq \mathrm{x}, \mathrm{y}, \mathrm{a} \vee \mathrm{z} ; \mathrm{y}_{1} \leq \mathrm{y}, \mathrm{z}, \mathrm{a} \vee \mathrm{x} ; \mathrm{z}_{1} \leq \mathrm{z}, \mathrm{x}$ ,$a \vee y$ and $x_{1} \vee y_{1} \vee z_{1} \vee a_{1}=t$ for $t \in S$. Hence $(a, b)$ is a super modular pair element in $S$.

Conversely, suppose $(a, b)$ be a super modular pair element in $S$. Then $b \leq t \leq a \vee x, a \vee y, a \vee z$, there exists $x_{1}, y_{1}$ ,$z_{1}$ in $S$, such that $x_{1} \leq x, y_{1} \leq y, z_{1} \leq z$, and $x_{1} \vee y_{1} \vee z_{1} \vee a_{1}=t$ for $t \in S$. By taking $b=x$ in above inequality we have $\mathrm{x} \leq \mathrm{t} \leq \mathrm{a} \vee \mathrm{x}, \mathrm{aV} \mathrm{y}, \mathrm{aV} \mathrm{z}$, there exists $\mathrm{x}_{1}, \mathrm{y}_{1}, \mathrm{z}_{1}$ in $\mathrm{S}$, such that $\mathrm{x}_{1} \leq \mathrm{x}, \mathrm{y}_{1} \leq \mathrm{y}, \mathrm{z}_{1} \leq \mathrm{z}$, but there may not exists an element $a_{1} \leq a$ such that $x_{1} \vee y_{1} \vee z_{1} \vee a_{1}=t$ for $t \in S$. Therefore $a$ is not join distributive element of $S$.

\section{Conclusion}

In this paper, a join distributive element in super modular semi lattice is defined and obtained every join distributive element of super modular semi lattice is distributive. Also it is proved that every directed below modular semi lattice is a super modular semi lattice. It is defined a super modular pair elements in join semi lattice and proved that, in a super modular semi lattice $\mathrm{S}$, if an element a is join distributive, the pair of elements $(a, b)$ is super modular pair elements of $\mathrm{S}$ for $\mathrm{b} \in \mathrm{S}$.

\section{References:}

[1]. Birkhoof.G- Lattice theory, Amer.Math.Soc, cal log publication XXV.Providence,R.I(1967)

[2]. Cornish,W.H.- Characterization of distributive and Modular semi lattices, Math.Japanica,22,159-174(1977).

[3]. Cornish, W.H.-Pseudo complemented modular semi lattice, J.Aust.Math.Sci.18 (1974) 239-251.

[4]. Iqbalunnisa and W.B.Vasantha-Characterization of Super modular lattices

[5]. J.Katrinak, Pseudo complementary Halbverbande, Mat.Casopis 18 (1968) 121-143.

[6]. Ramana Murthy, P.V. and Ramam,V.- Permutability of Distributive congruence relations in join semi lattice directed below, Math.Slovaca Vol.35,P.P 43-49,1985.

[7]. Rhodes, Joe. B-Modular and Distributive semi lattices, Trans.Amer, Math.Soc, Vol.201 (1976),31-41.

[8]. Talukder, M.R and Noor.A.S.A-Modular ideals of a join semi lattice directed below. SEA Bull.Math.Vol-22, P.P 215-218, 1978.

[9]. Venkateswara Rao,J and Sri Rama Ravi Kumar. E- Characterization of Super modular semi lattice, SEA Bull.Math.2010, Vol.34, P.P 1035-1041. 